\title{
Is it correct to trust each ultrasonography report blindly? a case report on misdiagnosis, diagnosis and management of acardiac twin pregnancy
}

\author{
Pooja Chandak*, Shobha Toshniwal
}

Department of Obstetrics and Gynecology, Toshniwal Chest Hospital and Maternity Home, Nanded, Maharashtra, India

Received: 24 March 2020

Accepted: 22 April 2020

\author{
*Correspondence: \\ Dr. Pooja Chandak, \\ E-mail: drpoojachandak@gmail.com
}

Copyright: (C) the author(s), publisher and licensee Medip Academy. This is an open-access article distributed under the terms of the Creative Commons Attribution Non-Commercial License, which permits unrestricted non-commercial use, distribution, and reproduction in any medium, provided the original work is properly cited.

\begin{abstract}
Multifetal gestation is often a high-risk pregnancy and especially the monochorionic twin pregnancy significantly contributes to fetal morbidity and mortality. Acardiac twinning, earlier known as chorioangiopagus parasiticus, is the most extreme manifestation of this condition. An acardiac twin is a rare complication of multifetal pregnancy, in the literature reported at an incidence of $1 \%$ of monochorionic twin pregnancies, i.e. 1 of 35,000 pregnancies. Often results from abnormal placental vascular anastomoses. This leads to twin reversal arterial perfusion with complex pathophysiology. Here authors present a case of acardiac twin pregnancy presented at 26 weeks with the ultrasonography report suggested?? Placental teratoma of size $11 \times 11 \times 13 \mathrm{~cm}$ with polyhydramnios as there was no reason to suspect something else as the picture described in the USG report with the polyhydramnios was fitting with the diagnosis of placental teratoma but as the scan was done at taluka place and the images provided were not clear authors decided to confirm the diagnosis from fetal medicine specialist as MTP was not the option for the patient as she was 28 weeks who confirmed that as a case of acardiac twin pregnancy and the case was managed accordingly.
\end{abstract}

Keywords: Acardiac twin pregnancy, Fetal medicine expert, Ultrasonography

\section{INTRODUCTION}

Multiple pregnancy accounts for $1.5 \%$ of all pregnancies among these the development of the acardiac anomaly is a rare complication of monozygotic multiple pregnancies. ${ }^{1}$ It was first described in the sixteenth century (Benedetti, 1533 and occurs in $\sim 1 \%$ of monozygotic twin pregnancies and in 1 out of 35000 deliveries.

The most widely accepted theory on the pathogenesis of acardius is the occurrence of a twin reversed arterial perfusion sequence (TRAP). One well developed normal pump twin and the other twin with absent cardiac structure acardiac who is hemodynamically dependant on normal pump twin are characteristics of this syndrome., ${ }^{2,3}$

\section{CASE REPORT}

A 22-year-old primigravida married since 1 year with spontaneous conception presented at 28 weeks of gestation with the ultrasonography report suggested?? Placental teratoma of size $11 \times 11 \times 13 \mathrm{~cm}$ with polyhydramnios. As there was no reason to suspect something else as a diagnosis because the picture of the mass lesion described in the USG report along with presence of with the polyhydramnios was fitting with the diagnosis of placental teratoma but as the scan was done at taluka place and the provided were not clear authors decided to confirm the diagnosis from fetal medicine specialist as the patient is past 20 weeks MTP was not the option for her. Before sending authors reviewed all the previous scans of the patient the patient underwent 3 ultrasonography's including the last one which suggested 
placental teratoma. The earliest scan she underwent was at 12 weeks suggested A single live intrauterine gestation of 12 weeks with normal choriodecidual complex. The anomali scan at 21 weeks was showing single live intrauterine fetus with no gross structural anomalies with $10.5 \times 5.3 \mathrm{~mm}$ acute subchorionic hemorrhage.

After the ultrasonography done by fetal medicine expert the final diagnosis was monochorionic diamniotic twin with acardia twin pregnancy with pump twin structurally being normal and presence of polyhydramnios with no hemodynamic compromise in pump twin with the acardiac twin volume of $1825 \mathrm{~cm}^{3}$ is fed by blood pumped from normal pump fetus through an abnormal arterial connection through placenta.

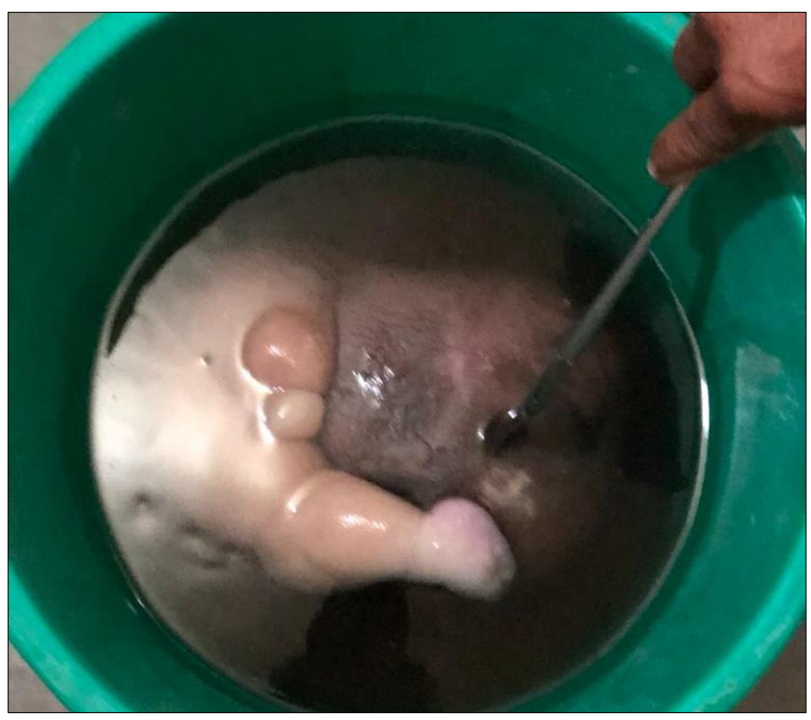

Figure 1: Photograph taken immediately after delivery.

For the management authors thought of weekly ultrasonography with doppler studies for the signs of hydrops and circulatory failure in pump twin and administration of steroids and the time of delivery would be decided based on doppler findings with elective caesarian section but as the patient was non affording for weekly monitoring authors advised her monitoring every fortnightly. The follow up scan after 2 weeks suggested normal doppler parameters of pump twin with biometry corresponding to 31 weeks and estimated fetal weight of $1.8 \mathrm{~kg}$. The volume of acardiac twin was $2490 \mathrm{~cm}^{3}$, the CPR (cerebro-placental ratio) was normal. The polyhydramnios was still there. In this weeks the course of antenatal steroids completed and the patient was again asked to undergo ultrasonography after $2 \mathrm{wks}$.The follow up USG suggested volume of acardiac twin was $3704 \mathrm{~cm}^{3}$ with fetal biometry corresponding to 33.4 weeks with estimated fetal weight of $2.1 \mathrm{~kg}$ but at this time the CPR ratio was increased to 1.09 , thus the decision of elective caesarian section take after completing a course og magnesium sulphate for neuro-protection. Section planned early in the morning with pediatrician stand by.
First the pump twin delivered by vertex presentation baby cried immediately after birth and handed over to pediatrician, the birth weight of pump twin was $1.8 \mathrm{~kg}$. The second acardiac twin delivered with the weight of 3 $\mathrm{kg}$. It was an irregular mass with ill-defined truncal structure with ill-defined lower limb buds and absent head and upper torso.

The acardiac twin born is kept in a bucket of formalin it was an ill defines truncal mass with ill-defined lower limb buds and absent head and upper body (Figure 1).

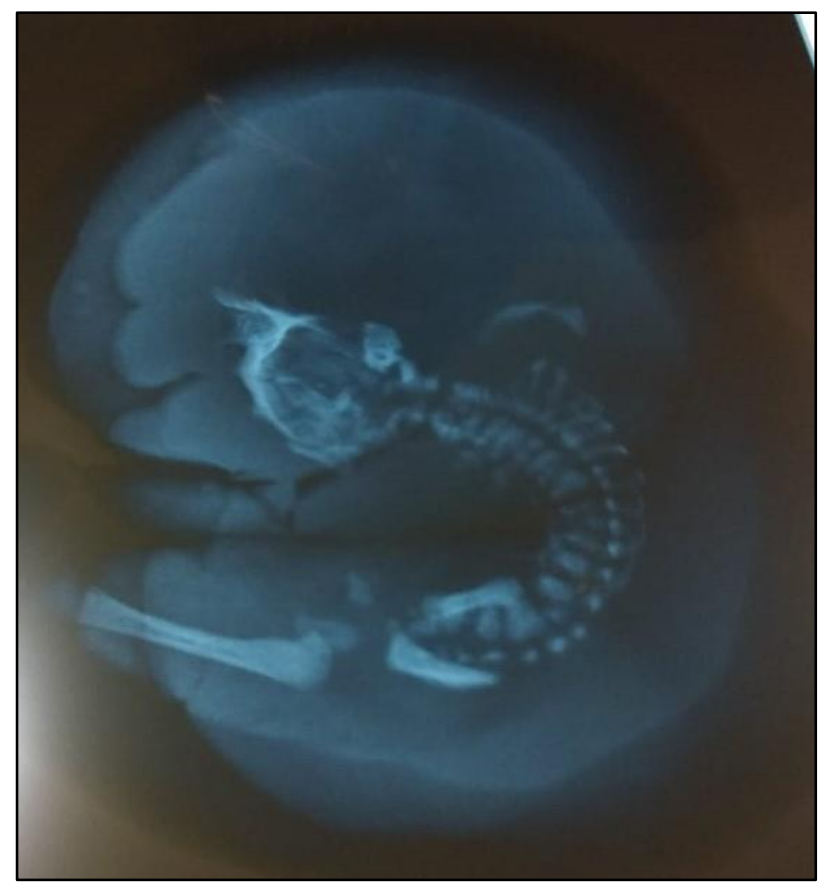

Figure 2: X-ray of acardiac twin: spine ending abruptly.

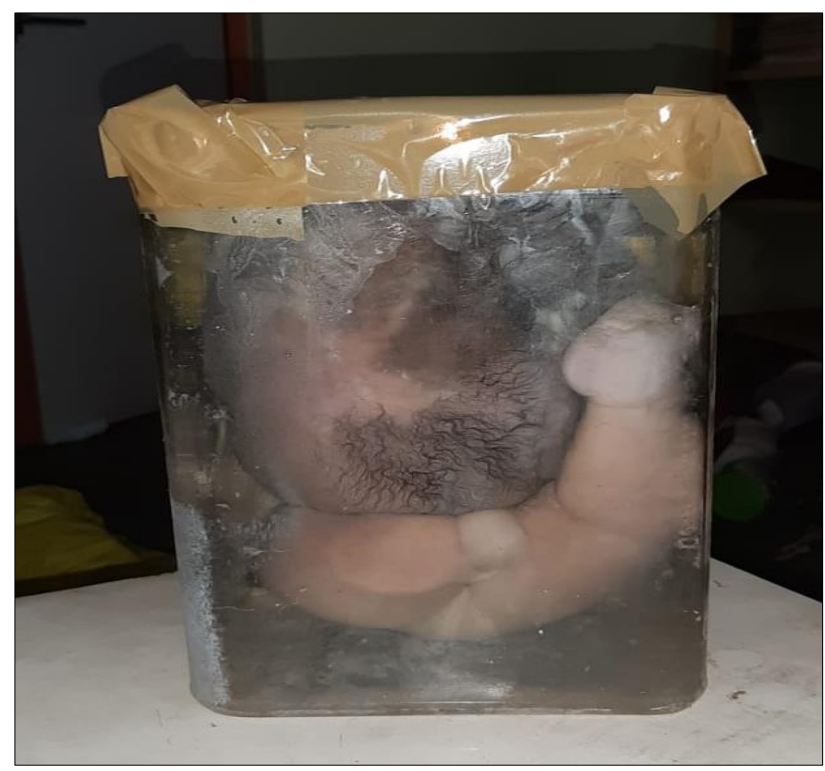

Figure 3: The mount specimen of acardiac twin. 
Section went uneventful. Paediatrician kept the pump twin in NICU for one day for all workup and the baby was given to mother as all the investigations were normal.

It was then given to pathology department of GMC, Nanded with the consent of parents for educational purpose (Figure 2).

The mount specimen of acardiac twin at pathology department of Dr. SCGMC Nanded, Maharashtra, India (Figure 3).

\section{DISCUSSION}

Twin reversed arterial perfusion sequence (TRAP) previously known as acardiac twin is a rare condition occuring in 1 in 35000 pregnancies and $1 \%$ of monochorionic twins. ${ }^{1,2}$ Acardiac anomaly usually occurs in monozygotic twins, although there are a few reports of dizygotic twins with a fused placenta. It is more common in female twins, and because the disorder is monozygotic, the twins are usually of same gender. In TRAP sequence the normal twin acts as pump twin which donates blood to the abnormal twin called recipient twin through an abnormal artery-to-artery or venous-to-venous communication in the placenta. This results in reversal of flow in the umbilical cord vessel of the recipient twin. Oxygenated blood enters the fetus through umbilical arterya and deoxygenated blood leaves the fetus through umbilical vein, which is the opposite of normal blood flow pattern in a fetus. ${ }^{4,5}$

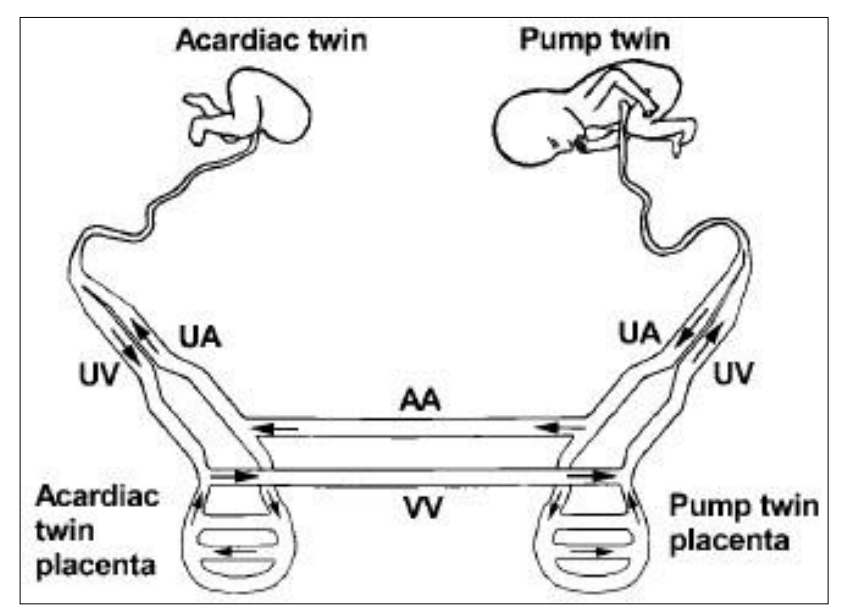

\section{Figure 4: Demonstration of blood circulation in} acardiac twins.

As a result of an imbalance in the inter-fetal circulation, the caudal aspect of acardiac fetus receives blood with relatively more oxygen than the upper torso, resulting in better development of lower body, as shown in lower diagrammed.

Associated congenital anomalies may present in about $9 \%$ of pump twins. This twin is often at high risk for congestive cardiac failure due to increased cardiovascular demand, resulting in preterm delivery. The overall perinatal mortality in pump twin is about $50-55 \% .^{6}$

Ultrasonography has assumed increasing importance in prenatal diagnosis of congenital anomalies. Using this technique, intrauterine diagnosis of acardiac twins has been made during the first trimester of pregnancy. Ultrasonography in acardiac twins reveals a normal pump twin with an acardiac twin. The pump twin may show signs of hydrops with hepatosplenomegaly, cardiomegaly, ascites and pleural effusion. The recipient twin has severe anomalies and may have an anencephaly. Its upper trunk and neck area will be thickened. Upper limbs are sometimes absent. Club feet and absent toes are often seen. Limb movements are sometimes visible in acardiac fetus. Polyhydramnios is common. If there are two sacs, polyhydramnios is found with the pump twin and oligohydramnios with the acardiac twin. The acardiac fetus usually has a two-vessel umbilical cord. Color Doppler velocimetry may help to determine the site of the vascular connection and assess circulatory health of the pump twin. An acardiac twin should be suspected in all monochorionic, malformed fetuses with cystic hygroma, generalized edema, and an absent cardiac pulsation with a nonfunctioning heart. ${ }^{7,8}$

Termination of pregnancy should be considered if acardiac twinning is diagnosed early in the pregnancy. However, early recognition and active management of the TRAP syndrome with maternal digoxin and indomethacin therapy can salvage the pump twin. This protocol has been reported to prevent congestive cardiac failure in the pump twin and polyhydramnios in the mother. ${ }^{9}$

Risk for cardiac insufficiency in the pump twin increases proportionally with increase in weight of recipient twin. Risk for congestive heart failure increases to $94 \%$ as the acardiac twin achieves a size more than half the size of the pump twin.

The management implies a periodic ultrasound examination of the pumping twin in order to early detect the signs of fetal hydrops or the alternation of the flows. The administration of corticosteroid therapy between 24 weeks and 34 weeks is important for pulmonary maturity, given the risk of premature birth. Over the years, many efforts have been made to treat TRAP. The interventions that can be performed are the following: laser ablation, bipolar cord coagulation, radiofrequency ablation (RFA). If it is decided that intrauterine surgery is needed, there are two types of approach, such as umbilical cord occlusion - by bipolar procedure (between 17 and 25 weeks of pregnancy)/ligature (after 26 weeks of pregnancy) and selective fetal reduction through fetoscopy. ${ }^{10,11}$ The other way is expectant management in which serial ultrasound with Doppler monitoring done as in this case and time and mode of delivery is decided based on doppler studies and weight of acardiac twin as in this case. 


\section{CONCLUSION}

Acardiac twin is a rare entity thus diagnosing it at early gestational age and planning correct management for it is a real challenge. Thus, it is necessary for us to review and go through every image provided by sonologist and not just blindly rely on the diagnosis provided by them.

Funding: No funding sources

Conflict of interest: None declared

Ethical approval: Not required

\section{REFERENCES}

1. Hrubec Z, Robinette CD. The study of human twins in medical research. N Engl J Med. 1984;310:43541.

2. Sogaard K, Skibsted L, Brocks V. Acardiac twins: pathophysiology, diagnosis, outcome and treatment. Six cases and review of the literature. Fetal Diagn Ther. 1999;14:53-9.

3. Cunningham FG, Grant NF, Leveno KJ, Gilstrap LC III, Hauth JC, Wenstrom KD. Williams Obstetrics. $21^{\text {st }}$ ed. New York: McGraw-Hill; 2001:783-784.

4. Pinet C, Colau JC, Delezoide AL, Menez F. Acardiac twins. Les jumeaux acardiaques. J Gynecol Obstet Biol Reprod. 1994;23:85-92.

5. Hanafy A, Peterson CM. Twin-reversed arterial perfusion (TRAP) sequence: case reports and review of literature. Aust N Z J Obstet Gynaecol. 1997;37:187-91.
6. Moore TR, Gale S, Benirschke K. Perinatal outcome of forty-nine pregnancies complicated by acardiac twinning. Am J Obstet Gynecol. 1990;163:907-12.

7. Ishimatsu J, Nakanami H, Hamada T, Yakushiji M. Color and pulsed Doppler ultrasonography of reversed umbilical blood flow in an acardiac twin. Asia Oceania J Obstet Gynaecol. 1993;19:271-5.

8. Al-Malt A, Ashmead G, Judge N. Color- flow and Doppler velocimetry in prenatal diagnosis of acardiac triplet. J Ultrasound Med. 1991;10:341-5.

9. Sepulveda W, Sfeir D, Reyes M, Martinez J. Severe polyhydramnios in twin reversed arterial perfusion sequence: successful management with intrafetal alcohol ablation of acardiac twin and amniodrainage. Ultrasound Obstet Gynecol. 2000;16:260-3.

10. Tan TYT, Sepulveda W. Acardiac twin: A systematic review of minimally invasive treatment modalities Ultrasound Obstet Gynecol. 2003;22:40919.

11. Weisz B, Peltz R, Chayen B, Oren M, Zalel Y, Achiron $\mathrm{R}$, et al. Tailored management of twin reversed arterial perfusion (TRAP) sequence. Ultrasound Obstet Gynecol. 2004;23:451-5.

Cite this article as: Chandak $\mathrm{P}$, Toshniwal S. Is it correct to trust each ultrasonography report blindly? a case report on misdiagnosis, diagnosis and management of acardiac twin pregnancy. Int J Reprod Contracept Obstet Gynecol 2020;9:2628-31. 